\title{
Abnormal left heart function after operation for atrial septal defect
}

\author{
Hywel Davies ${ }^{1}$, G. Charles Oliver, William J. Rappoport, and Nikos Gazetopoulos \\ From Guy's Hospital, London S.E.I, U.K., and St. Foseph's Hospital, Denver, Colorado, U.S.A.
}

Post-operative data have been presented in seven patients with atrial septal defect. In five of them, residual patency of the atrial septum was found at cardiac catheterization, but in two the defect had been closed.

All showed evidence of 'left-sided dysfunction', expressed either as an increase in the pulmonary arterial wedge pressure or the left ventricular end-diastolic pressure or both. The reasons for these findings are not clear, though in several there were indications of impaired right ventricular compliance and possible transmission of raised right-sided pressures to the left side of the heart through a still patent atrial septum. This could not, however, be the mechanism in all cases, and dysfunction of the left ventricle has been seen in two patients in whom the defect was securely closed. The cause of this phenomenon in these selected cases remains obscure.

Opinions have differed about the management of patients with atrial septal defect, especially in the older age-groups. The merits of surgical versus medical therapy in patients who are in the fifth or later decades of life have been discussed by Daicoff, Brandenburg, and Kirklin (1967), Wolf et al. (1968), and Gault et al. (1968).

In assessing the advisability or otherwise of operation, the ultimate fate of the operated patients must be taken into account as well as the operative risk, and too little well-founded information is available on this point. There is no doubt, however, that many patients do very well indeed for many years after operation.

Over the past years we have encountered some patients in whom there have appeared signs of left heart dysfunction after operation, in some cases accompanied by evidence of persistence of an interatrial communication, but in others when the defect has been apparently soundly closed. We feel that these cases merit recording, not because they are representative of the behaviour of patients who have undergone an operation for atrial septal defect but because they illustrate unpredictable but real complications in the postoperative course.

\section{Subjects and methods}

Seven patients have been encountered among

Received 18 February 1970.

${ }^{1}$ Address for reprints: Division of Cardiology, University of Colorado School of Medicine, Denver, Colorado, U.S.A. those operated on for atrial septal defect, who have shown evidence of left ventricular dysfunction after operation. They form the subject of this report. Clinical details are given in Table $\mathrm{I}$.

Pre-operative catheterization studies were performed in six of the patients; in the seventh, pressure measurements were made at the time of operation. Post-operative data were obtained by catheterization in all patients, with exercise measurements in all but one.

The techniques used in Cases I to 4 have been described elsewhere (Davies and Gazetopoulos, 1966). In Cases 5 to 7 the methods were similar with minor variations. Studies of the left heart were in addition performed either via percutaneous arterial puncture (Cases I and 3), by crossing the still patent atrial septum (Cases I and 4), or via a brachial arteriotomy (Cases 5 to 7 ).

\section{Symptoms and signs}

In all patients some unusual feature in the postoperative course led to the performance of the second study. Thus, Case $I$, despite the usual regression in heart size and electrocardiographic changes, insisted that her pre-operative dyspnoea was unrelieved, and five years after operation noted a worsening of dyspnoea and swelling of the ankles. Case 2 developed atrial fibrillation, unresponsive to drugs or to later electrical cardioversion, at the time of operation. Six years after operation she began to notice breathlessness on exertion, and was found to have a right ventricular lift as well as some increase in the jugular venous pressure, with some increase in heart size and electrocardiographic voltage ( $R^{1}$ in $\left.\mathrm{VI}\right)$ as compared with the early post-operative findings.

Case 3 was admitted to hospital with rapid atrial dysrhythmia and pulmonary oedema four years after operation (Fig. I). Case 4 continued 
TABLE I Details of patients studied

\begin{tabular}{|c|c|c|c|c|c|c|c|c|c|c|}
\hline $\begin{array}{l}\text { Case } \\
\text { No. }\end{array}$ & $\begin{array}{l}B S A \\
\left(m .^{2}\right)\end{array}$ & Sex & Lesion & $\begin{array}{l}\text { Age } \\
\text { at op. } \\
(y r .)\end{array}$ & $\begin{array}{l}\text { Age at } \\
\text { post-op. } \\
\text { study } \\
(y r .)\end{array}$ & $\begin{array}{l}\text { Rhythm at } \\
\text { post-op. study }\end{array}$ & $\begin{array}{l}\text { Disabilit } \\
\text { Pre-op. }\end{array}$ & $\begin{array}{l}\text { ty gradet } \\
\text { Post-op. }\end{array}$ & $\begin{array}{l}\text { Interval } \\
\text { operation to } \\
\text { symptoms }\end{array}$ & $\begin{array}{l}\text { Complaints } \\
\text { at post-op. } \\
\text { admission }\end{array}$ \\
\hline $\mathbf{I}$ & $\mathrm{I} \cdot 4$ & $\mathbf{F}$ & ASD & 36 & 42 & Normal sinus & $3 \mathrm{~A}$ & $3 A$ & Immediately & $\begin{array}{l}\text { Dyspnoea, } \\
\text { ankle swelling, } \\
\text { cyanosis }\end{array}$ \\
\hline 2 & $\mathrm{I} \cdot 8$ & $\mathrm{~F}$ & ASD & 29 & 37 & Atrial fib. & 2 & $3 A-3 B$ & $6 \mathrm{yr}$. & Dyspnoea \\
\hline 3 & $I \cdot 9$ & $\mathbf{M}$ & $\mathrm{ASD}+\mathrm{PS}$ & 35 & 39 & Atrial flutter & ${ }^{*} \mathrm{~B}$ & & $4 \mathrm{yr}$. & $\begin{array}{l}\text { Dyspnoea, } \\
\text { dizziness, } \\
\text { ankle swelling }\end{array}$ \\
\hline 4 & $\mathrm{I} \cdot 6$ & $\mathrm{~F}$ & ASD & 44 & 50 & Atrial fib. & $3 B$ & $3 A$ & $3 \mathrm{yr}$. & Dyspnoea \\
\hline 5 & $\mathrm{r} \cdot 8$ & $\mathbf{M}$ & ASD & 29 & 32 & Normal sinus & 0 & 0 & $2 \mathrm{yr}$. & None \\
\hline 6 & $I \cdot 9$ & $\mathbf{F}$ & $\mathrm{ASD}$ & 21 & 22 & Normal sinus & 2 & 2 & Immediately & $\begin{array}{l}\text { Dyspnoea, } \\
\text { ankle swelling }\end{array}$ \\
\hline 7 & $2 \cdot 0$ & $\mathbf{M}$ & ASD & 35 & 36 & Normal sinus & $3 \mathrm{~A}$ & $3 \mathrm{~A}$ & Immediately & $\begin{array}{c}\text { Dyspnoea, } \\
\text { fatigue }\end{array}$ \\
\hline
\end{tabular}

* Reversed to sinus rhythm during the post-operative catheterization.

† Disability grade according to N.Y. Heart Association, Grade 3 being divided into 3A and 3B after Donald, Bishop, and Wade (1954).

after operation to have atrial fibrillation, unresolved cardiomegaly, and a widely split and virtually fixed second sound, with no resolution of her electrocardiographic abnormalities. Case 5 was found on post-operative clinical examination to have unusually prominent ' $a$ ' waves in the jugular venous pulse. Case 6 likewise had raised venous pressure and ankle oedema which necessitated diuretic therapy. Case 7 had complained that there was no improvement in pre-operative symptoms of dyspnoea and fatigue.

FIG. I Chest x-ray in Case 3, showing pulmonary venous congestion, five years after operation.

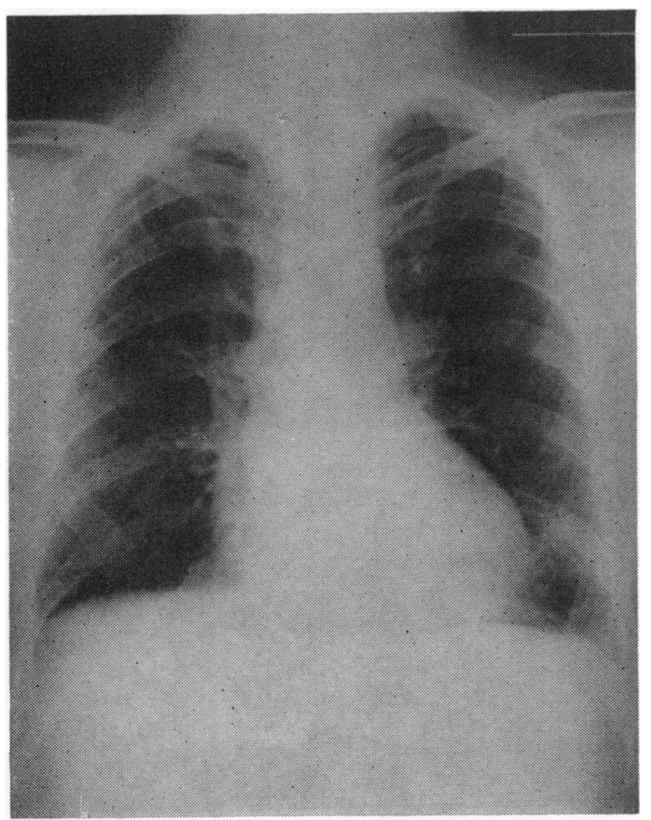

\section{Results}

Haemodynamic data are shown in Table 2. Various aspects of the findings will be described separately.

Residual patency of the interatrial septum In five of our seven cases we have found evidence of a remaining defect. In two the findings indicate that it was firmly closed.

In Case I direct passage of the defect by the catheter confirmed that the arterial desaturation on exercise was due to septal patency, and dye curves from the inferior vena cava showed an early appearance at the ear. In Case 2 arterial desaturation occurred on exercise, presumably (though not in this case proved to be) due to septal patency. In Case 3 the arterial oxygen saturation fell on exercise, and dye curves showed a right-to-left shunt at atrial level. In Case 4 a large left-to-right shunt at atrial level was found. In Case 6 the hydrogen curves were difficult to interpret, but may have been positive in the pulmonary artery. There was no rise in oxygen saturation at any point in the right heart, nor was there any arterial desaturation on exercise. The data were interpreted as showing probably a small residual defect, hydrogen-positive but oxygen-negative. Cases 5 and 7 showed negative hydrogen curves in the pulmonary artery, and the arterial oxygen saturation did not fall on exercise. The defects were considered to be closed in these two patients.

Shunts Of the five patients with evidence of a residual defect, only in Case 4 was there a significant left-to-right shunt. In Cases I, 
TABLE 2 Haemodynamic data

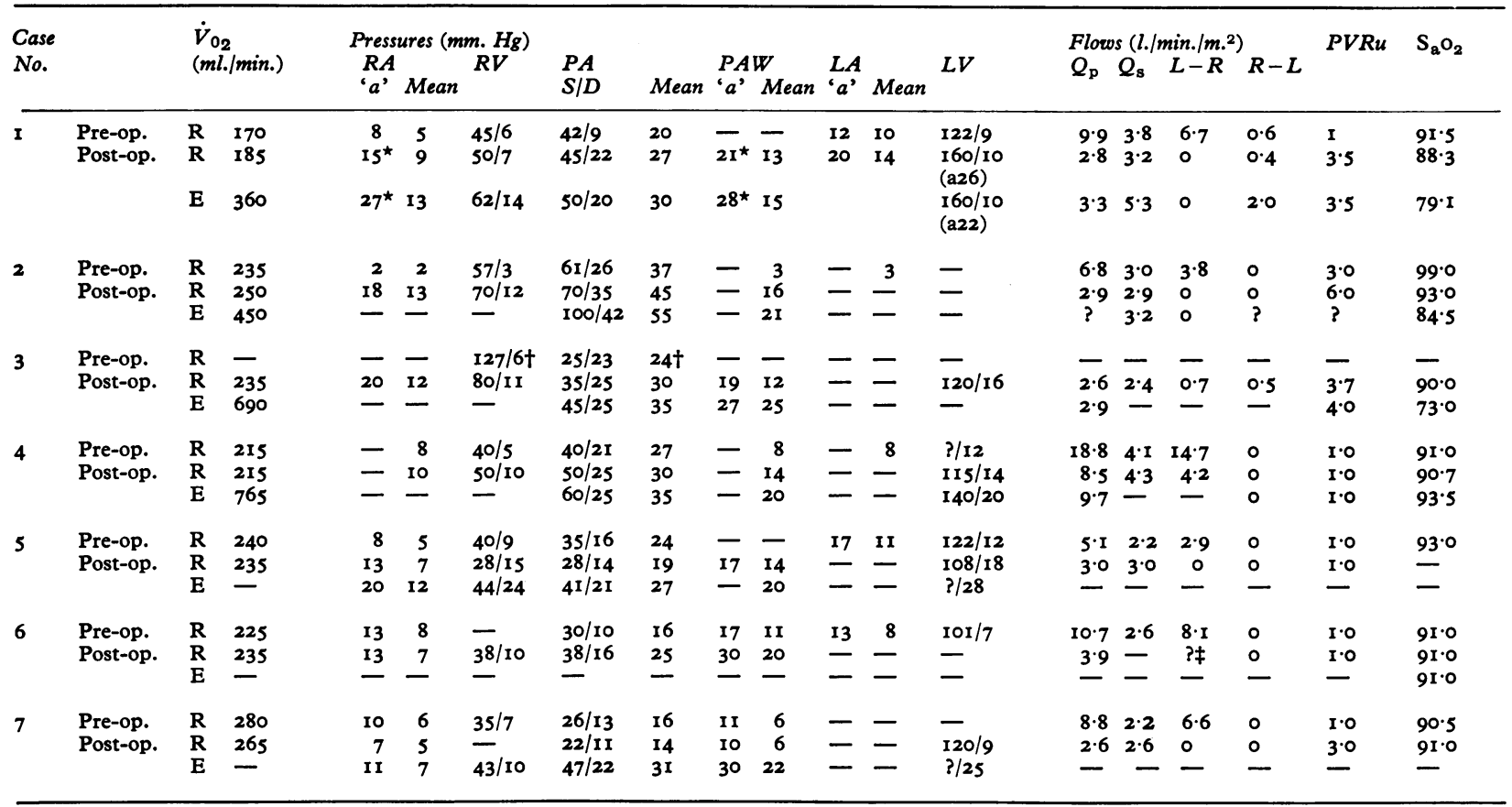

$\star$ Cannon waves.

+ Pressures taken on operating table.

¥ Hydrogen curves suggest small left-to-right shunt.

$R$, rest; $\mathrm{E}$, exercise; $\mathcal{Q}_{\mathrm{p}}$, pulmonary flow; $Q_{s}$, systemic flow; $L-R$, left-to-right shunt; $R-L$, right-to-left shunt; PVR, pulmonary vascular resistance in Wood units; $\mathrm{S}_{\mathrm{a}} \mathrm{O}_{2}$, systemic arterial oxygen saturation.

2 , and 3 the shunt was dominantly right-toleft, not surprising in Case 3 since he had pulmonary stenosis, but an unexpected finding in Cases $I$ and 2. In Case 6 equivocal evidence of a small left-to-right shunt was found on hydrogen curves.

Pressures Abnormally raised pressures, either in the pulmonary arterial wedge position, the left atrium, or the left ventricle, were found in all patients.

Fig. 2 shows the pressure tracings from the right atrium and pulmonary vein in Case $\mathbf{I}$. Fig. 3 from the same patient shows strikingly abnormal transmitted ' $a$ ' waves in the left ventricle. Fig. 4 shows the raised right atrial and wedge pressures in Case 2. Fig. 5 illustrates that the wedge pressure in Case 3 rose to a mean level of $26 \mathrm{~mm}$. $\mathrm{Hg}$ on exercise. Fig. 6 shows the abnormal contour of the right atrial pressure tracings in this patient, indicating impaired ventricular compliance. Fig. 7 and 8 are from Case 5, showing minimal increase of left atrial and left ventricular pressures before operation, with frank increase in diastolic pressures on both sides of the heart after operation. Fig. 9 illustrates the increase in wedge pressure after operation in Case 6, and Fig. Io the abnormal pressures in the pulmonary arterial wedge position and in the left ventricle in Case 7.

Pulmonary vascular resistance There was a conspicuous rise in pulmonary vascular resistance, compared to pre-operative values,

FIG. 2 On the left the pre-operative (1959) right atrial pressure tracing is seen. On the right the tracings from the right atrium and pulmonary vein recorded in 1964 . The similarity between right atrial and pulmonary venous tracings is evident, both being raised and showing prominent ' $a$ ' waves. Case $I$, resting.

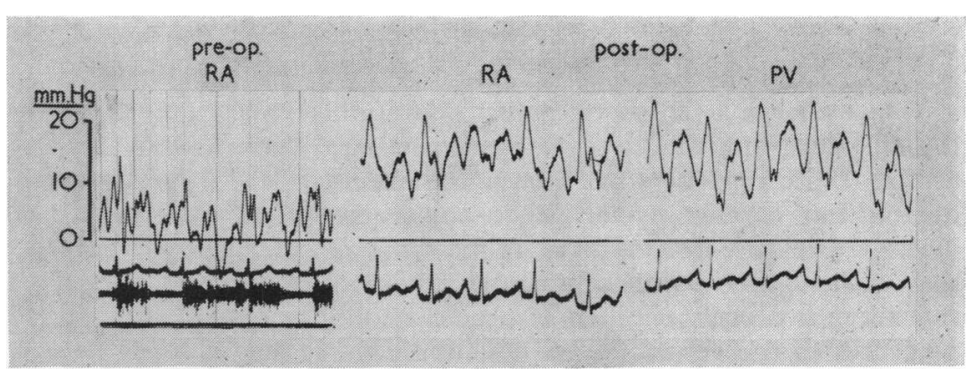




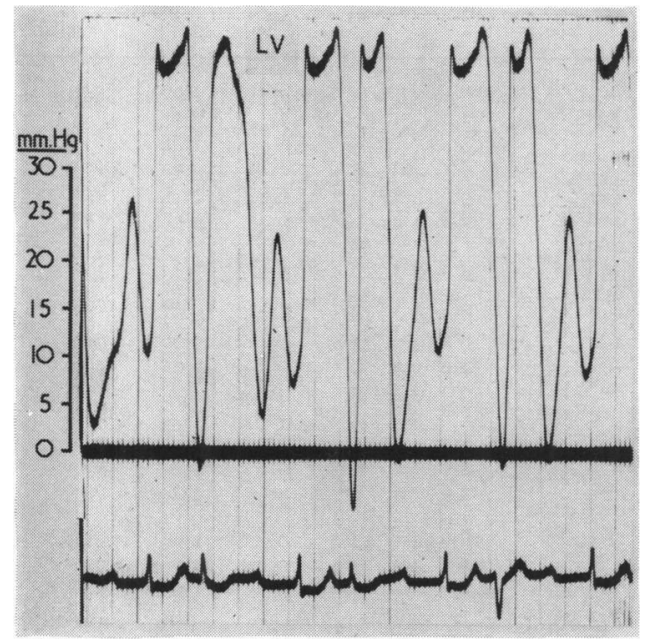

FIG. 3 Pressure tracings from the left ventricle in Case I (recorded when the patient was suffering from digitalis excess two days before the post-operative tracings of Fig. 2). The ' $a$ ' waves transmitted into the left ventricle are strikingly abnormal.

in Cases 1,2 , and 7, but no change in Cases 4 , 5, and 6. No pre-operative measurements had been made in Case 3.

\section{Discussion}

The question of left ventricular function has been of interest to students of atrial septal defect before and since Dexter raised the issue in his St. Cyres lecture to the National Heart Hospital of London in 1955. Some have felt that the left ventricle tends to be hypoplastic in this condition, and that it may have difficulty in accepting the load of the systemic circulation when the relief mechanism of the atrial septal defect is abolished as a result of operation. Others, notably Tikoff et al. (1965), have stated their view that when congestive cardiac failure supervenes in a patient with atrial septal defect it is due to failure of the left ventricle and not the right, in that right ventricular failure manifests itself as a diminution in its output and of the volume of the left-to-right shunt rather than in an increase in end-diastolic pressure.

When a large atrial septal defect is present the pressures in the two atria are similar, though there may be small phasic variations during the cardiac cycle. Since the enddiastolic pressure in a ventricle is the same as that of its corresponding atrium, provided that there is no valvular stenosis, the diastolic pressures in the ventricles are essentially the

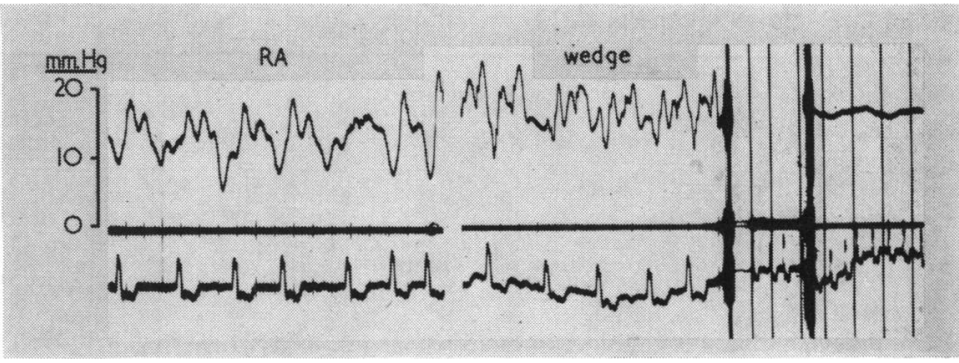

FIG. 4 Case 2: resting pressures from the right atrium and pulmonary arterial wedge (with mean) six years after operation. Both are raised.

FIG. 5 Case 3: pulmonary arterial wedge pressure on exercise, showing a mean value of $26 \mathrm{~mm} . \mathrm{Hg}$, five years after operation.

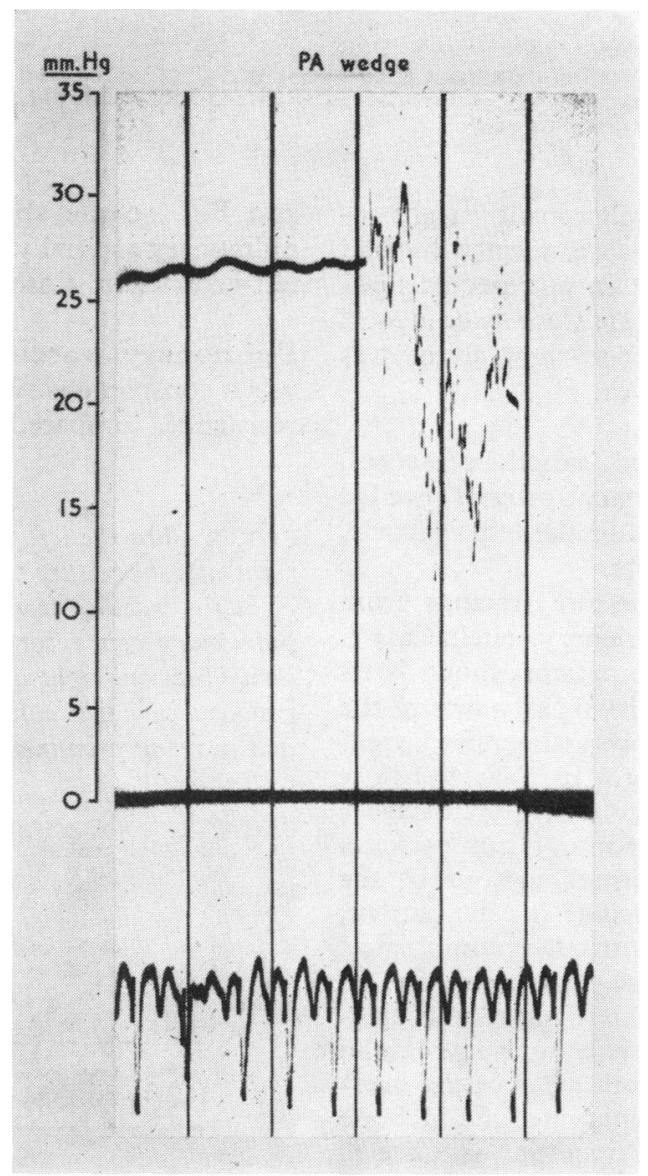


FIG. 6 Case 3: right atrial pressure tracings before $(a)$ and after (b) DC cardioversion. The prominent ' $y$ ' descent in the latter signifies impaired right ventricular compliance, five years after operation.

same. Thus, failure of either ventricle, or both, must be accompanied by similar effects on the two atria and their respective venous systems. For a large left-to-right shunt to be present, the size of the defect must presumably be considerable, but transmission of pressure from one atrium to the other and hence to the opposite ventricle may not require a large defect. In atrial septal defect, therefore, an increase in the end-diastolic pressure in the left ventricle is a necessary consequence of a rise in that of the right, and vice versa.

Tikoff et al. (1965) quote the evidence of Brecher and Opdyke (I95I) as support for the concept that the right atrial pressure can remain normal despite the development of right ventricular failure in large atrial septal defects: in addition, the work of Rodbard and Kohn (1957) using a circulation model, and that of Hawthorne, Brownlee, and Spellman (1956) indicating that systemic venous pressure rises in dogs with surgically-created atrial septal defects after the production of left ventricular failure by induced aortic insufficiency, support this concept. It would indeed be surprising if this did not occur, for there can be no question that left ventricular failure in atrial septal defect does cause systemic venous hypertension. Whether or not this is the usual mechanism in the natural atrial septal defect remains, however, unproved. The main changes in the heart with atrial septal defect are in the right atrium and ventricle, the latter being much dilated in patients in heart failure, while the left ventricle remains unhypertrophied. Since the brunt of the lesion falls on the right ventricle, failure of this chamber would not be an unnatural consequence, and it would be strange if later in the course of the natural evolution of the disease its enddiastolic pressure should not rise, with the necessary consequences on the left side of the heart and the pulmonary venous pressure. The finding of orthopnoea and paroxysmal nocturnal dyspnoea in patients who are in heart failure as a result of atrial septal defect thus becomes comprehensible.

FIG. 7 Case 5: before operation. The left ventricular end-diastolic pressure and the left atrial pressure are slightly raised.
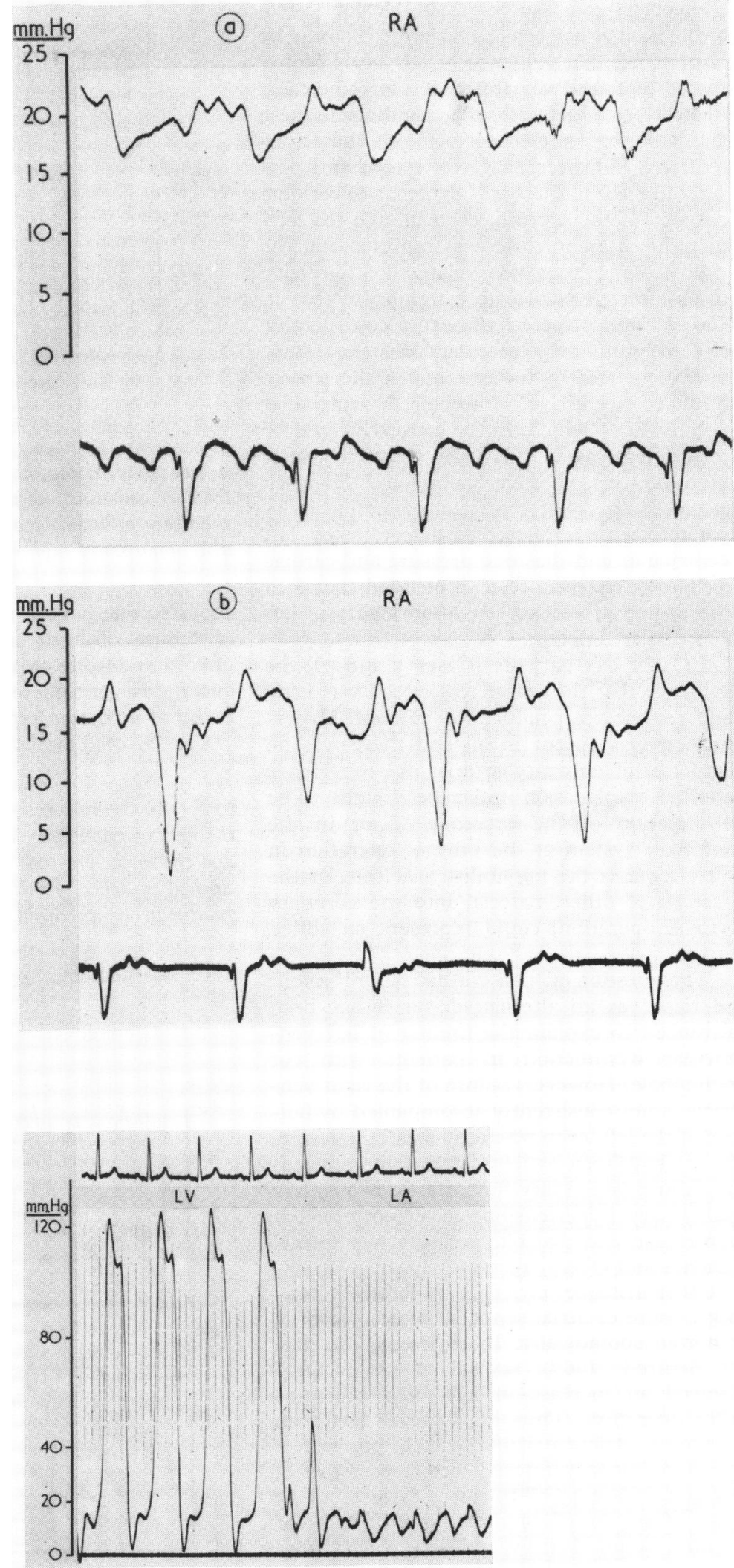
According to the theses of Dexter (1956) and Tikoff et al. (1965), therefore, it would be anticipated that evidence of left heart failure would be found after operation in some cases of atrial septal defect, and our findings in these selected cases appear to bear out their contentions. However, in Cases $I$ to 4 and possibly in Case 6, there was evidence of residual patency of the septum, even though the leftto-right shunt in three was minimal and the right-to-left shunt was relatively impressive in amount. It is probably significant that in Cases $I$ and 2 there had been a considerable rise in pulmonary vascular resistance since operation, and in Cases $I$ and 3 there were findings suggestive of impaired ventricular compliance - which, in the context, would be expected to assail the right ventricle rather than the left. Flamm, Cohn, and Hancock (1968) studied left ventricular function in 15 patients with atrial septal defect, using left ventricular end-diastolic pressure and cardiac output as criteria. They concluded that 8 of these showed at least one abnormality of left ventricular function.

In 2 of our patients (Cases 5 and 7), the evidence that the defect was closed was firm, and yet left heart failure was present. Hypertension was absent in all and there was no evidence of coronary arterial disease. Hence another explanation must be sought. The observation of the presence of air in the coronary system at the time of operation in Case 2 raises the possibility that this, or the passage of other material into the coronary tree at operation, could represent an added factor.

The question of 'pan-cardiac failure' might be raised as an alternative, for it has been advanced to explain the finding of left ventricular dysfunction in patients with cor pulmonale. However, failure of the right ventricle is not consistently accompanied by failure of the left, even when the former is severe, for we have seen patients with right ventricular failure (secondary for instance to primary pulmonary hypertension) in whom the left ventricular end-diastolic pressure was normal (Davies and Overy, 1970).

Other instances of left heart failure following closure of atrial septal defects have been reported sporadically. In reviewing the data of Arnfred (1967), several of his patients showed an increase in left-sided pressures after operation. Thus his Case 18, with an unclosed atrioventricular canal, showed a mean pulmonary arterial wedge pressure of $20 \mathrm{~mm}$.; Case 45 of $19 \mathrm{~mm}$.; Case 50 of 15 mm.; Case 6I of $17 \mathrm{~mm}$; and Case 85 of I5 mm. Cohn, Morrow, and Braunwald (1967)

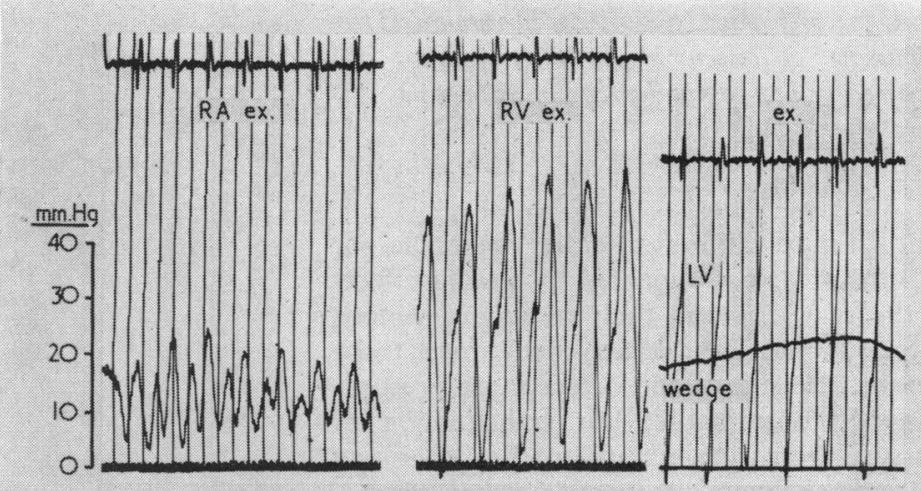

FIG. 8 Case 5: exercise tracings taken $2 \frac{1}{2}$ years after operation. Tall ' $a$ ' waves are seen in the right atrium, both right and left ventricular end-diastolic pressures are raised, and the mean pulmonary arterial wedge pressure is also abnormally high.

reported one patient who developed evidence of failure of both sides of the heart after operation despite only a small residual defect, and he was considered to have a cardiomyopathy of unknown type.

Case 6 of Tikoff et al. (1965) is another

FIG. 9 Case 6: tall ' $v$ ' waves are seen in the resting pulmonary arterial wedge tracing, and the mean pressure is raised. There was no clinical evidence of mitral insufficiency seven months after operation.

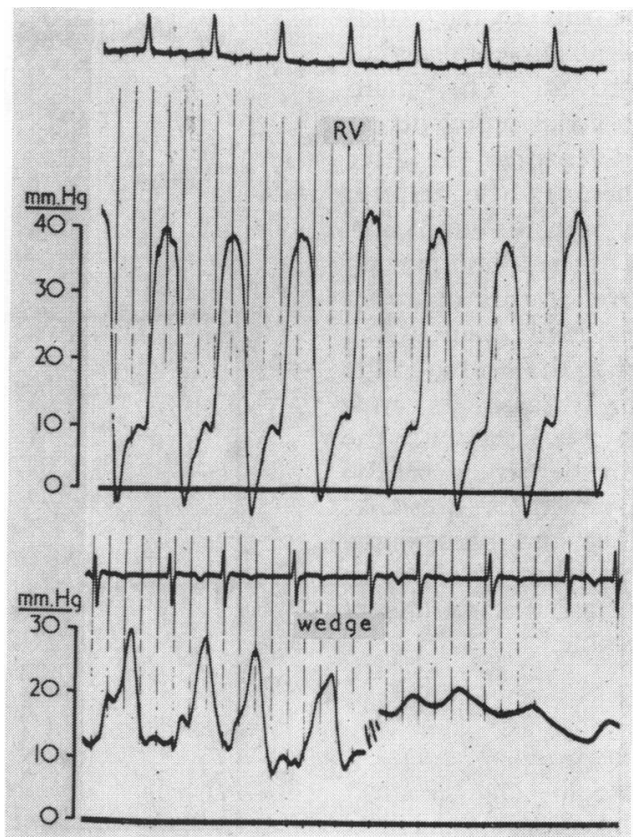


similar example. After operation, when the defect was apparently closed, evidence of biventricular failure was found with an increase in the pulmonary artery wedge pressure, the patient having developed peripheral oedema and pulmonary congestion. Leuker, Vogel, and Blount (1969) have studied the response to exercise of $2 \mathrm{r}$ patients after operation for atrial septal defect, and found abnormal behaviour in six (one with complete heart block) and borderline responses in three.

The function of the left ventricle in patients with heart disease who have been subjected to major operative procedures continues to be an intriguing topic. We have observed unexplained left ventricular dysfunction after mitral valve surgery, and while coronary arterial disease is always a possibility to explain this, it is unlikely that in the present series of relatively young patients it is a major factor.

Sellers et al. (1966) have commented on the problem of air embolism during operations for atrial septal defect and the measures that they take to deal with it. Before concluding that surgical trauma is responsible for the post-operative findings, however, it should be noted that both Cases 5 and 6 showed slight increases in atrial pressure before operation, which gave rise to clinical suspicion of an unusual situation.

Whatever the cause, the present evidence of post-operative morbidity might reasonably be taken into account in deciding on the management of asymptomatic patients with atrial septal defect.

Cases I-4 were seen and studied at Guy's Hospital. They were under the care of the late Dr. Charles Baker and of Dr. Dennis Deuchar.

\section{References}

Arnfred, E. (1967). A clinical and hemodynamic evaluation of the results of surgical correction of atrial septal defect. Fournal of Cardiovascular Surgery, 8, 93.

Brecher, G. A., and Opdyke, D. F. (195I). The relief of acute ventricular strain by the production of an interatrial septal defect. Circulation, 4, 496.

Cohn, L. H., Morrow, A. G., and Braunwald, E. (I967). Operative treatment of atrial septal defect: clinical and haemodynamic assessments in 175 patients. British Heart fournal, 29, 725.

Daicoff, G. R., Brandenburg, R. O., and Kirklin, J. W. (1967). Results of operation for atrial septal defect in patients forty-five years of age and older. Circulation, 35 and 36, Suppl. I, p. 143.

Davies, H., and Gazetopoulos, N. (1966). Haemodynamic changes on exercise in patients with leftto-right shunts. British Heart fournal, 28, 579.

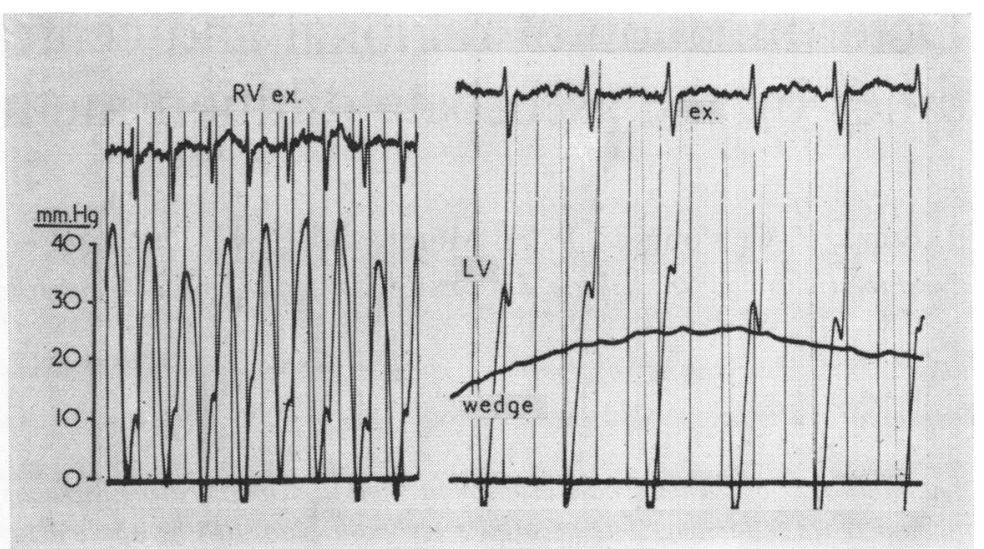

FIG. IO Case 7: right and left ventricular end-diastolic pressures are raised on exercise, as is the pulmonary artery wedge pressure, six months after operation.

, and Overy, H. R. (1970). Left ventricular function in chronic lung disease. Chest. In the press.

Dexter, L. (1956). Atrial septal defect. British Heart fournal, 18, 209.

Donald, K. W., Bishop, J. M., and Wade, O. L. (1954). A study of minute to minute changes of arteriovenous oxygen content difference, oxygen uptake and cardiac output and rate of achievement of a steady state during exercise in rheumatic heart disease. Fournal of Clinical Investigation, 33, I 146.

Flamm, M. D., Cohn, K. E., and Hancock, E. W. (1968). Left ventricular function in atrial septal defect. (Abstract.) Clinical Research, 16, 136.

Gault, J. H., Morrow, A. G., Gay, W. A., and Ross, J. (I968). Atrial septal defect in patients over the age of forty years. Circulation, 37, 26r.

Hawthorne, E. W., Brownlee, G. V., and Spellman, M. W. (I956). Prophylaxis against acute pulmonary edema and death in dogs with aortic insufficiency following renal artery constriction afforded by prior construction of an atrial septal defect. American fournal of Physiology, 185, 479.

Leuker, R. D., Vogel, J. H. K., and Blount, S. G. (1969). Cardiovascular abnormalities following surgery for left-to-right shunts; observations in atrial septal defects, ventricular septal defects and patent ductus arteriosus. Circulation, 40, 785 .

Rodbard, S., and Kohn, R. (1957). Dynamics of atrial septal defects. Federation Proceedings, 16, 108.

Sellers, R. D., Ferlic, R. M., Sterns, L. P., and Lillehei, C. W. (I966). Secundum type atrial septal defects: early and late results of surgical repair using extracorporeal circulation in 275 patients. Surgery, 59, I55.

Tikoff, G., Schmidt, A. M., Kuida, H., and Hecht, H. H. (1965). Heart failure in atrial septal defect. American fournal of Medicine, 39, 533.

Wolf, P. S., Vogel, J. H. K., Pryor, R., and Blount, S. G., Jr. (1968). Atrial septal defect in patients over 45 years of age. Merits of surgical versus medical therapy. British Heart fournal, 30, 1 I 5. 